\title{
Correction: Optimal sustainability assessment method selection: a practitioner perspective
}

\author{
K. Koppiahraj ${ }^{1}$ S. Bathrinath ${ }^{1} \cdot$ V. G. Venkatesh ${ }^{2}$ (D) $\cdot$ Venkatesh Mani $^{3} \cdot$ Yangyan Shi $^{4}$
}

(c) Springer Science+Business Media, LLC, part of Springer Nature 2021

\section{Correction to: Annals of Operations Research https://doi.org/10.1007/s10479-021-03946-z}

Author Yangyan Shi affiliations missed during proof corrections by vendor and should be read as: Department of Management, Macquarie Business School, Macquarie University, Sydney, Australia.

Original article has been updated.

Publisher's Note Springer Nature remains neutral with regard to jurisdictional claims in published maps and institutional affiliations.

The original article can be found online at https://doi.org/10.1007/s10479-021-03946-Z.

S. Bathrinath

V. G. Venkatesh vgv1976@gmail.com

$\bowtie$ Yangyan Shi

1 Department of Mechanical Engineering, Kalasalingam Academy of Research and Education, Krishnankoil, Tamilnadu 626126, India

2 EM Normandie BusinessSchool, METIS Lab, Le Havre, France

3 Montpellier Business School, Montpellier, France

4 Department of Management, Macquarie Business School, Macquarie University, Sydney, Australia 